\title{
Trevor Coward: 'I never thought that just by making an ear for someone, it would change the way they are and give them so much more confidence - it's quite incredible really'
}

Interview by Adrian O'Dowd

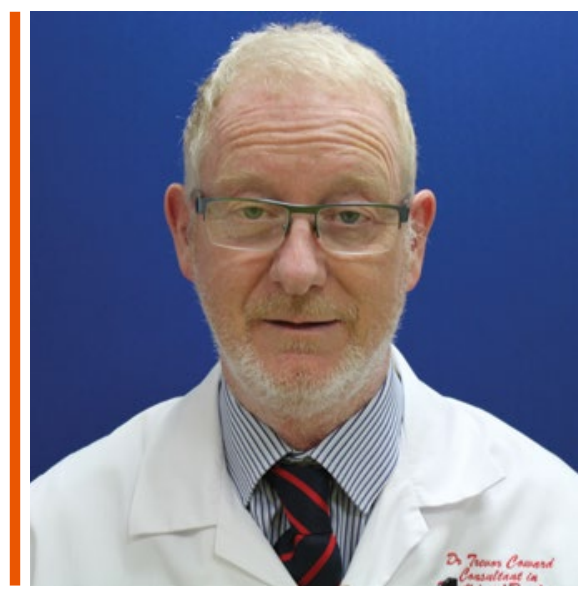

$\mathrm{M}$ axillofacial and craniofacial prosthetic rehabilitation may sound like the domain of highly technical specialist practice, but their purpose couldn't be simpler - they can give patients their life back.

So believes Trevor Coward, maxillofacial prosthetics expert based at King's College London (KCL) who is celebrating 40 years working at the university this year.

Trevor is Reader/Consultant in

Maxillofacial \& Craniofacial Prosthetic Rehabilitation at the Academic Centre of Reconstructive Science within the Faculty of Dentistry, Oral and Craniofacial Sciences at $\mathrm{KCL}$, a role that clearly suits someone with his level of enthusiasm for helping patients.

Ever-improving technological advances help with his work, but they merely serve to improve the level of care that he and colleagues can provide to patients who need their help.

Trevor Coward is an expert in maxillofacial prosthetics based at King's College London who leads the Academic Centre of Reconstructive Science which is developing ground-breaking 3D printers to produce more realistic, longer-lasting facial prostheses for patients.

He splits his time between his clinical work at the trust's Facial Rehabilitation Clinic, support clinical sessions for the oncology surgery department at Guy's and St Thomas' NHS Foundation Trust, laboratory teaching, and research. students, he then became a lecturer in maxillofacial and craniofacial technology, before becoming a consultant at King's College Hospital in 2008.

'What appealed to me about this specialty was the ability to rehabilitate patients and

\section{'What appealed to me about this specialty was the ability to rehabilitate patients and see people change'}

\section{Prosthodontics specialty}

After qualifying as a dental technician in 1980 at King's College School of Medicine \& Dentistry, Trevor then went on to study advanced prosthodontics, a specialty he was quickly drawn to.

After being a dental instructor for undergraduate and postgraduate dental see people change,' he explains. 'When you first see them, they don't have a prosthesis. Then to be able to provide an eye, ear, nose or even a combination of those things and see how it changes someone's perspective on life - that's the appeal.

'Often you'd see patients that were coming out of cancer therapy and 


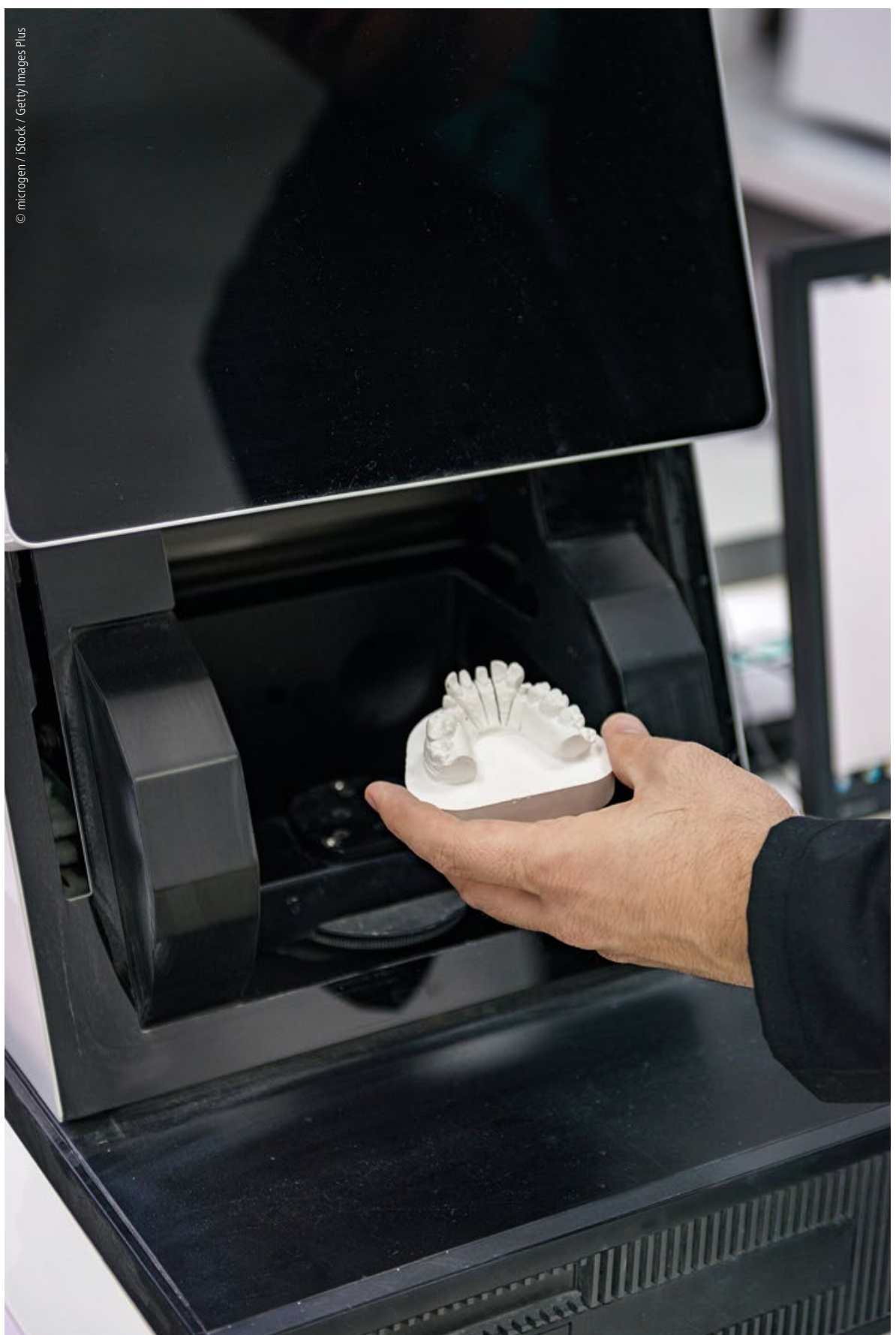

\section{'Often you'd see patients that were coming out of cancer therapy and they really were quite down. To be able to rehabilitate them so that they have a different perspective is quite rewarding. For some people, it's huge and life changing.'}

4 they really were quite down. To be able to rehabilitate them so that they have a different perspective is quite rewarding. For some people, it's huge and life changing. I never thought that just by making an ear for someone, it would change the way they are and give them so much more confidence than without - it's quite incredible really'

Around 8,300 people are diagnosed with mouth cancer each year in the UK and in terms of facial prosthetics, for the whole
UK, maxillofacial prosthetists make around 7,500 per year.

\section{Reconstructive centre}

One of the most impressive achievements during his time at King's has been the creation of the Academic Centre of Reconstructive Science (ACRS), internationally recognised as a centre of excellence for maxillofacial and craniofacial rehabilitation.

The centre, which opened officially in 2016, is funded jointly by KCL and Guy's and St Thomas' NHS Foundation Trust (GSTT), and the research it does deals with reconstructing or regenerating craniofacial structures missing due to cancer or congenital defects.

Originally a maxillofacial unit at King's College Hospital and then moved to Guy's Hospital in 2011, Trevor explains: 'Then when we got to 2016, we joined the academic unit which was the King's College side with the Guy's Hospital side so we became one unit rather than two.

'The idea is that our academic work informs our clinical practice for the research that we do. Evidence-based research then helps our treatment of clinical patients.'

The ACRS, which offers three MSc programmes, has global appeal, as he says: 'We've had about 34 countries which have sent people to us for training.'

\section{D printing of silicone prostheses}

The ACRS houses a 3D printing centre, which serves many purposes, particularly in helping produce facial prostheses needed by patients who have lost eyes, ears, noses or combinations of these because of trauma such as a traffic accident, surgery for cancerous tumours, or congenital malformations.

Currently, the manufacture of prostheses involves taking an impression of the defect site, pouring a working model in stone, carving/sculpturing a wax trial prosthesis, and then creating a part mould into which pigmented silicone is placed before curing. It is also sometimes necessary to add further pigmentation when a prosthesis is fitted onto the patient - a process involving five to seven patient appointments.

Trevor and his colleagues are seeking to improve and speed up the process, using digital technology to plan and provide for facial prostheses. 
4 'We are still working on it,' he says. 'Previously, you couldn't print silicone. We developed a printer that could print silicone elastomers and we worked with a company in developing silicone that was suitable for $3 \mathrm{D}$ printing. The next step which we need to do - which we're trying to get grants for - is to put the colour into it.

'It could also be used for orthotics and if you upscaled, it could be used for body prostheses.'

Silicone is an ideal material to use for facial prosthetics, he explains, saying: 'We can change its characteristics ie softness or hardness. The idea is you end up with a nice bio-compatible material, which is nicely pigmented and matches the natural surrounding tissue of the patient's face. of the COVID-19 pandemic, but they are already being used in various ways and are easily proving their worth, says Trevor.

The ACRS team already provides 3D printing services to GSTT for restorative dentistry, oncology, plastic reconstruction, ENT [ears, nose and throat] and orthognathic surgery planning, designing/ supplying preoperative templates, surgical cutting guides, surgical wafers and preoperative models for surgery planning and rehearsal.

'We were hoping that the floor that I currently work on was going to be redeveloped and there was discussion that we would have a specific area there for our $3 \mathrm{D}$ printers so we could link up with the medical physics department of GSTT and become one service delivering across the

\section{'At the moment, we are embedded in dental therefore we are probably dealing with most of oncology and the dental school, whereas medical physics might be dealing with different groups such as orthopaedics.'}

'At the moment, the prosthesis that we make by sculpturing and a moulding process takes a number of appointments. If we could $3 \mathrm{D}$ print this, you could reduce the number of appointments.

'You could hold the file in a databank and then when the person needed a new ear or a new nose, you could then reprint that file, providing the colour hadn't changed on the patient too much. Taking digital impressions would be better than actually taking an impression of someone's face because that's quite an invasive procedure.'

Trevor's team has around 250 facial prosthetic patients and the prostheses need to be re-made every 18 months because they discolour.

'Part of our programme is that we have $\mathrm{PhD}$ students working on colour science to try and increase the longevity of the colour of the prosthesis,' he says.

\section{Wider use of 3D printing}

Plans to have a dedicated area for the 3D

printers at KCL have been delayed because whole of King's Healthcare Partners', says Trevor.

'At the moment, we are embedded in dental therefore we are probably dealing with most of oncology and the dental school, whereas medical physics might be dealing with different groups such as orthopaedics.'

\section{Face masks during COVID-19}

One recent project involving Trevor's team has been efforts to improve the facemasks used by COVID-19 frontline NHS staff.

Scientists at the Healthcare Technologies Institute at University of Birmingham, KCL and Imperial College London are working to improve the seal and fit of facemasks used in hospitals.

Since the pandemic began, it has become apparent that there are sometimes issues with prolonged wearing of personal protective equipment (PPE) masks such as abrasion and bruising of facial tissues.

KCL's Academic Centre of Reconstructive Science and University of Birmingham have been running a collaborative project to explore the feasibility of providing person-specific reusable, medical grade silicone seals to fit with the generic facemasks currently used in the NHS.

The silicone interface, designed by researchers from the Centre for Custom Medical Devices at Birmingham, would help to improve the mask seal thereby reducing exposure risk as well as reducing fitting time and improving comfort for users.

Making use of the 3D capture technology at the ACRS, individual faces are being digitally captured and the silicone seals $3 \mathrm{D}$ printed to fit the individual's face. The silicone seal was designed by the KCL team but the fit and adaptation to the face was created by the Birmingham group.

Trevor says: 'At the moment we know that masks fail for certain types of people so we designed one that will have different seals that will fit against the face and fit most people. We have got three sizes of that and it will fit around $85 \%$ of people, but there'll be this $15 \%$ outside of that where we have to customise it and take an imprint of the subject's face in order to make the seal specifically for them.

'This is now going to a small business who are going to upscale this and I think they got a grant from the government to take it forward.'

\section{Future projects}

Trevor's field of practice is one that, by its nature, is always evolving and he is already looking at the next big thing.

'Following on from the COVID masks, we are trying to develop masks that fit patients as well', he says.

'There's a huge area where masks don't fit properly and therefore there's a lot of patients with acute and chronic conditions who would benefit from a mask that fits and is comfortable.

'We are also doing a lot of work with surgical teams in providing pre-operative planning by providing stents where you can cut it exactly into the shape and length that you want and you could see pre-bend plates and bars prior to going to surgery so it reduces the surgical time and allows the surgeon to rehearse the surgery, should they wish to.'

The future of this specialty promises to be an exciting one that will only improve patients' quality of life. 